\title{
EXPANSÃO URBANA E DINÂMICA MARINHA DA PRAIA DA COSTA NO MUNICÍPIO DE BARRA DOS COQUEIROS - SERGIPE
}

\author{
Tais Kalil Rodrigues(a), Sinthia de Araújo Barreto ${ }^{(b)}$, Eliel Santos de Souza ${ }^{(c)}$

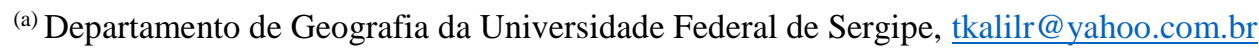 \\ (b) Departamento de Geologia da Universidade Federal de Sergipe, sinthia.barreto@gmail.com \\ ${ }^{(c)}$ Departamento de Geografia da Universidade Federal de Sergipe, eliel.1997s@gmail.com
}

\section{Eixo: DINÂMICA E GESTÃO DE ZONAS COSTEIRAS}

\begin{abstract}
Resumo
A expansão urbana no município de Barra dos Coqueiros, em Sergipe, aumentou significativamente nos últimos 10 anos, principalmente depois da construção da ponte interligando o município com a capital do estado, Aracaju. O Objetivo desse trabalho é analisar a expansão urbana próximo à linha de costa, em decorrência da construção de condomínios, hotéis e casas e investigar a dinâmica marinha na região da praia da Costa. Sendo assim, foi realizado um estudo histórico sobre a área e analisado como durante os últimos anos essa expansão urbana se intensificou, para obter os resultados do clima de ondas utilizou-se o programa Sistema de Modelagem Costeira SMC - Brasil. Com isso verificou-se que a ocupação próxima ou sobre a linha de costa na área em estudo traz riscos à população local, fazendo-se necessário a adoção de ações para a gestão da área em estudo.
\end{abstract}

Palavras chave: Expansão urbana; clima de ondas; tempestades.

\section{Introdução}

A zona costeira, patrimônio natural do Brasil (BRASIL, 1988), é uma região de extrema importância para vida e para as atividades humanas, pois se diferencia pela sua interação entre o mar, a terra e o ar, abrigando diversos ecossistemas: mangues, dunas, praias, restingas, etc. Essa interação influencia na redução da amplitude térmica, na localização estratégica para fins comerciais e a existência de diversos recursos naturais.

As ondas, juntamente com marés e ventos, tornam a zona costeira um setor altamente dinâmico, intervindo de maneira significativa na mobilização, circulação e transporte de sedimentos, definindo as características morfológicas das praias (ALMEIDA et. al. 2015). A região costeira é caracterizada por uma grande diversidade de ambientes, muitos deles extremamente frágeis, que estão submetidos a processos de degradação causados pela crescente ocupação do litoral.

Os ambientes costeiros por suas características atraem a ocupação humana, a qual usa para atividades turísticas, lazer, exploração de recursos e circulação de bens e pessoas, o que torna um ambiente de riqueza tanto ecológica quanto econômica. Entretanto, a zona costeira é um ambiente altamente instável e sensível e o seu uso desordenado acaba por comprometer a sua qualidade estética e ambiental, pois as atividades antrópicas requerem muitas vezes a construção de obras costeiras como portos e marinas que alteram profundamente o equilíbrio dos processos de transporte de sedimentos, consequentemente, 


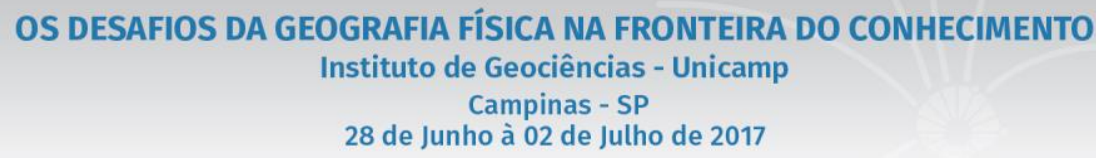

causando modificações no posicionamento da linha de costa ao longo do tempo, como erosão ou progradação (ESTEVES, 2004). Assim, a zona costeira apresenta-se como espaço de contradições, pois de um lado há uma área de grande relevância ecológica, destacando-se como um ambiente dinâmico e vulnerável e do outro apresenta grande potencial econômico, reunindo um grande contingente populacional e variadas atividades econômicas, as quais podem gerar situações de riscos para a integridade da região (MARIA, 2009).

O estado de Sergipe é um dos 17 estados costeiros do Brasil, tendo uma extensão litorânea de 168 km, dividida em três setores pelo Programa de Gerenciamento Costeiro Estadual GERCO/SE: Litoral Norte, Litoral Centro e Litoral Sul. A ocupação do litoral sergipano é marcado pela interferência do Estado a partir da construção de obras de infraestrutura. Este é o caso da Praia da Costa no município da Barra dos Coqueiros que teve seu espaço litorâneo valorizado após a construção da Ponte Construtor João Alves sobre o rio Sergipe, em 2006, a qual facilitou o acesso para a capital sergipana, Aracaju, alterando a dinâmica populacional do município, principalmente, da região litorânea. Portanto, torna-se relevante compreender a expansão urbana, como também, avaliar a dinâmica marinha da área de estudo, utilizandose do Sistema de Modelagem Costeira (SMC) para avaliar os impactos dos eventos oceanográficos extremos na linha de costa e orientar a adoção de ações para a gestão da zona costeira nos municípios litorâneos.

\section{2. Área de estudo}

A área de estudo compreende a Praia da Costa localizada no município da Barra dos Coqueiros, o qual possui uma extensão de $26 \mathrm{~km}$ de litoral divido por três praias: praia da Atalaia Nova com $5 \mathrm{~km}$ de extensão, praia da Costa com $3 \mathrm{~km}$ e praia do Jatobá com $18 \mathrm{~km}$ (Figura 01). O município faz parte da região metropolitana de Aracaju, estando localizado no setor leste do estado de Sergipe, limita-se ao Norte com o município de Pirambu, separado pelo rio Japaratuba; ao Sul, Leste e Sudeste pelo Oceano Atlântico; ao sudoeste com o município de Aracaju, separado pelo rio Sergipe e a Oeste e Noroeste com o município de Santo Amaro das Brotas, separado pelo canal Pomonga (COSTA, 2013).

A sede municipal tem uma altitude de 8 metros e coordenadas geográficas de $10^{\circ} 54^{\prime} 32^{\prime \prime}$ de latitude sul e 3702'19" de longitude oeste. A população municipal, segundo estimativas do Instituto Brasileiro de Geografia e Estatísticas (IBGE) no ano de 2016, é de 29.248 habitantes numa área de 89,598 km², com uma densidade demográfica de aproximadamente 326, $43 \mathrm{hab} / \mathrm{km} 2$.

O clima úmido e quente é caracterizado com precipitação média anual é de $1417 \mathrm{~mm}$, sendo o período de maior concentração de chuvas de abril a julho, resultado da atuação das massas Tropical Atlântica e, principalmente, massa Polar Atlântica. O mês de maio é o mais chuvoso com média de $251 \mathrm{~mm}$ e 
XVII Simpósio Brasileiro

de Geografia Fisica Aplicada

I Congresso Nacional

de Geografia Física

\section{OS DESAFIOS DA GEOGRAFIA FÍSICA NA FRONTEIRA DO CONHECIMENTO \\ Instituto de Geociências - Unicamp \\ Campinas - SP \\ 28 de Junho à 02 de Julho de 2017}

dezembro o mês mais seco com $40 \mathrm{~mm}$, a temperatura média anual é de $25,6^{\circ} \mathrm{C}$ com baixa amplitude térmica. Os ventos predominantes são os alísios de Sudeste e Nordeste.

A economia é composta pelas atividades agropecuárias, a pesca, a exploração do sal, única riqueza mineral da região, o comércio, a indústria e o turismo. Os pontos turísticos são as suas praias, Atalaia Nova, Jatobá e praia da Costa. O município tem apresentado uma crescente expansão urbana nos últimos anos desde a inauguração, no ano de 2006, da ponte que liga o município com a capital do estado, Aracaju. Por ser um município muito próximo da capital e pela acessibilidade o município tem o seu espaço valorizado, especialmente as regiões costeiras, as quais são alvo da especulação imobiliária, havendo a implantação de vários condomínios fechados de luxo, isto tem impulsionado a ocupação do litoral.

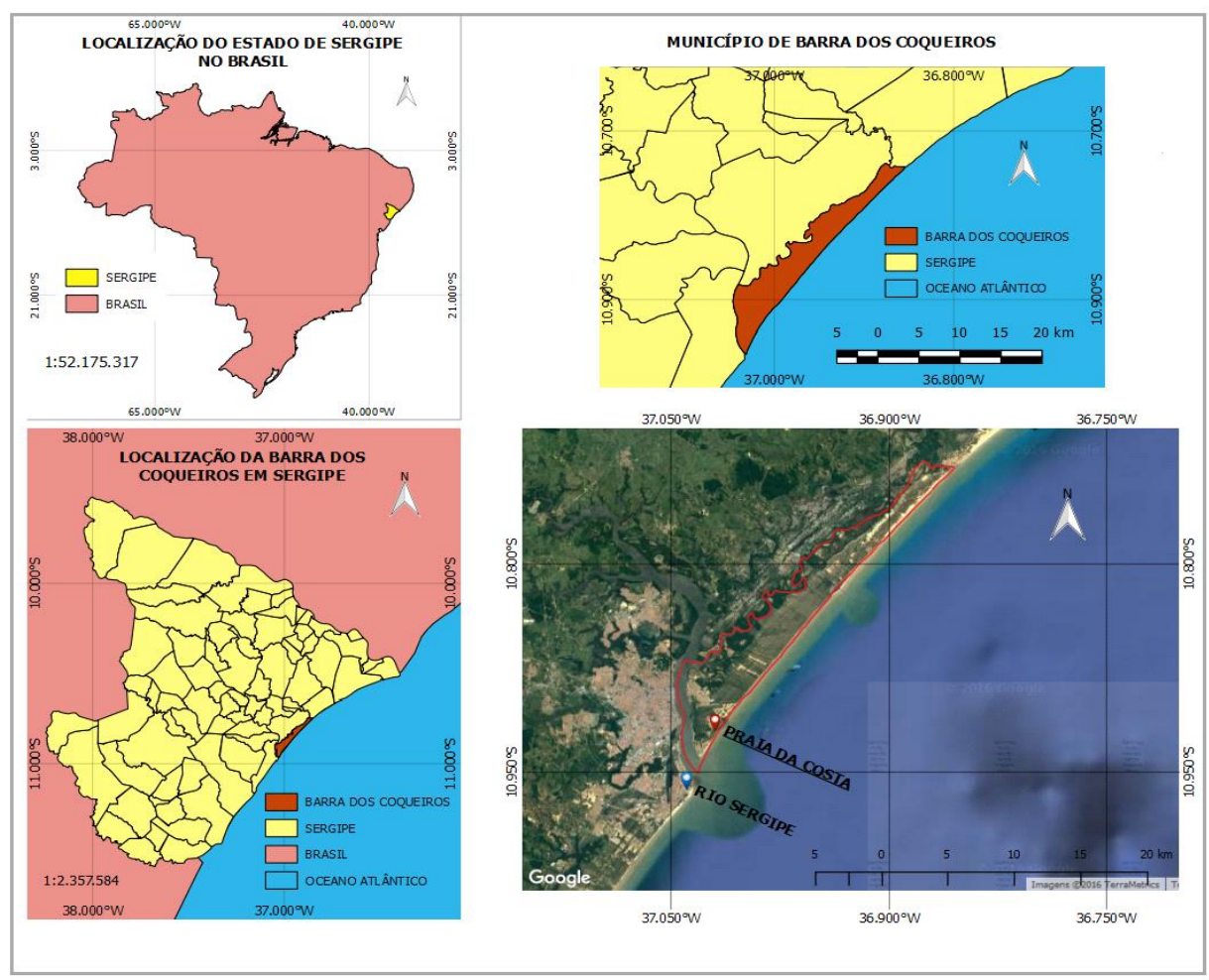

Figura 01: Mapa de localização da área de estudo.

\section{Materiais e Métodos}

Para a realização da análise de expansão e ocupação urbana do município, foi realizado o levantamento de dados quantitativos da população da Barra dos Coqueiros no período de 50 anos, análise de fotografias aéreas e imagens de satélites, levantamento bibliográfico sobre área de estudo.

Em campo foi realizada a caracterização morfodinâmica, de susceptibilidade à erosão e inundação e de nível de ocupação da zona costeira. A Praia da Costa e sua zona costeira adjacente também foram caracterizadas quanto à sua diversidade ecológica e presença de ecossistemas sensíveis. 
A análise da dinâmica marinha foi realizada com o Sistema de Modelagem Costeira do Brasil (SMC Brasil), o SMC foi inicialmente desenvolvido pelo Instituto Hidráulico Ambiental da Cantábria (IH Cantábria) da Universidade da Cantábria, e trata-se de um software ou uma ferramenta computacional que combina metodologias de trabalho, bases de dados de cartas náuticas e modelos numéricos orientados para o estudo e/ou solução de problemas na zona costeira. Assim, a partir do SMC-Brasil, podem ser executados diferentes modelos numéricos, que permitem realizar análises em curto, médio e longo prazo de uma praia (CAMUS et al., 2013).

Para a modelagem de ondas foi utilizada a base de dados batimétricos obtida a partir do módulo IHDATA (BACO) do SMC-TOOLS. Para a análise estatística de ondas, o SMC disponibiliza um banco de dados denominado Downscaled Ocean Waves (DOW) obtido a partir do processo de reanálise (downscaling), para águas intermediárias e rasas, do seu banco de dados Global OceanWaves, com série temporal de 1948 a 2008 (resolução a cada hora), calibrados e validados com medições instrumentais de bóias oceânicas e por satélites altimétricos.

A análise estatística de ondas para a área de estudo, para condições médias e extremas, foi realizada para o Ponto 1 (ponto DOW), de latitude $-10.973^{\circ} \mathrm{S}$ e longitude $-36.961^{\circ} \mathrm{W}$, com cota batimétrica de $14,92 \mathrm{~m}$, utilizando o módulo AMEVA do SMC-Brasil. Assim foram geradas informações sobre alturas de ondas (Hs), maré meteorológica (MM), maré astronômica (MA), períodos de pico (Tp) e direções de ondas (Dir). Este ponto foi escolhido pela sua localização e por apresentar os resultados mais significativos de alturas e períodos de ondas entre os pontos testados.

\section{Resultados e Discussões}

\subsection{Expansão urbana da área de estudo}

Inicialmente o processo de ocupação da Barra dos Coqueiros ocorreu influenciado pelas atividades do setor primário, destacando-se como principais vetores da ocupação a cocoicultura, a extração da mangaba e a pesca. Entretanto, até a década de 1960, a ocupação territorial se limitava, praticamente, a sede municipal e a pequenas localidades rurais com dificuldades de comunicação. Outro espaço ocupado corresponde à localidade da Atalaia Nova, com destaque para a atividade de pesca e a segunda residência. Essa baixa ocupação era resultada da difícil acessibilidade restringindo a ocupação a pequenas comunidades pelo município.

Entre 1980 e 1991 a população barra-coqueirense aumentou devido à implantação do Terminal Portuário Marítimo Inácio Barbosa e da expectativa criada pela construção do Polo Petroquímico, além do crescimento vegetativo (PEREIRA; WELLINGTON, 2013). Na década seguinte há o incentivo às atividades turísticas impulsionadas pelas ações do Programa de Desenvolvimento do Turismo no 


\section{OS DESAFIOS DA GEOGRAFIA FÍSICA NA FRONTEIRA DO CONHECIMENTO \\ Instituto de Geociências - Unicamp \\ Campinas - SP \\ 28 de Junho à 02 de Julho de 2017}

Nordeste (PRODETUR/NE I), aproveitando o elevado potencial ambiental do município. Equipamentos turísticos começam a ser instalados, principalmente, na Praia da Costa e Atalaia Nova.

Entretanto, a construção da Ponte Construtora João Alves sobre o rio Sergipe, em 2006, foi o grande vetor da ocupação e expansão urbana no município. A ponte permitiu que o município de Barra dos Coqueiros, até então isolado e sendo apenas possível o seu acesso através de barco, foi interligado através da ponte à capital Aracaju, promovendo melhor acessibilidade entre os dois municípios, provocando a expansão e valorização do município. Em 1960, a quantidade de habitantes do município se limitava a apenas 4.447 segundo o IBGE, e já no ano de 2010 houve um aumento para 24.976 habitantes, reflexo da expansão urbana a partir da ponte Construtor João Alves. O setor imobiliário, atraído pelos novos espaços, foi importante na ampliação das áreas urbanas a partir da construção de condomínios fechados, bem como a construção de hotéis e resorts (figura 02), a ocupação expande-se por diversas áreas do município, com destaque para as regiões litorâneas, as quais são os principais alvos desta expansão. Neste processo há a retirada da vegetação nativa, restinga, manguezal e coqueiros, desmatando extensas áreas que serão utilizadas para a instalação da infraestrutura urbana. Alguns dos novos condomínios construídos no município encontram-se muito próximo da linha de costa, assim como o hotel mostrado na figura 2D, e que já sofre um intenso processo de erosão devido a sua proximidade com o mar. Segundo o Projeto Orla (MMA, 2006), o ideal seria que a delimitação da orla marítima para áreas urbanizadas com 50 metros de proteção e 200 metros para áreas desocupadas, demarcadas na direção do continente a partir da linha de preamar ou do limite final de ecossistemas, tais como as caracterizadas por feições de praias, dunas, áreas de escarpas, falésias, costões rochosos, restingas etc. 

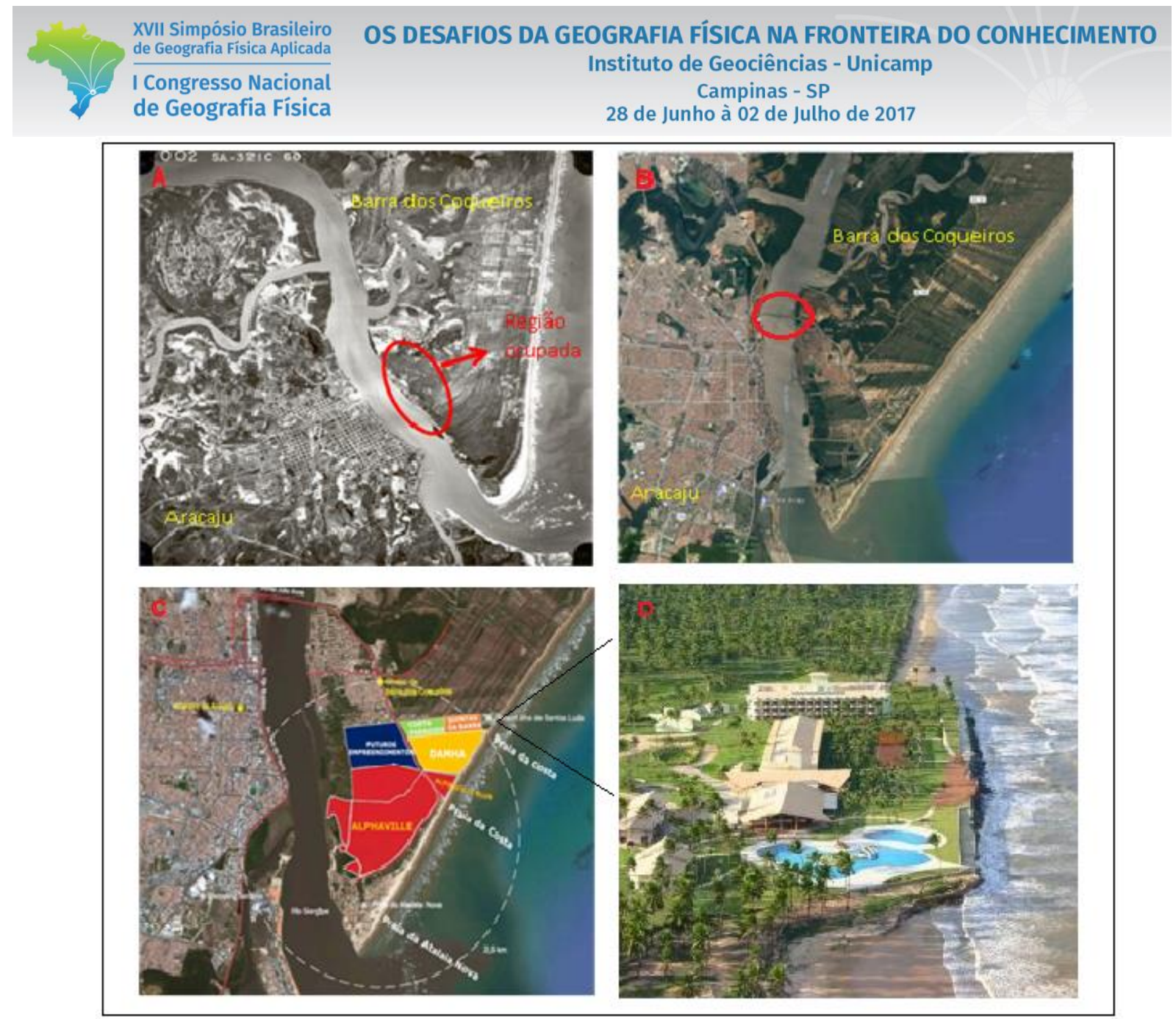

Figura 2 - A: Ocupação da Barra dos Coqueiros limitada à sede municipal em 1965; B: Barra dos Coqueiros em 2016, com destaque para a Ponte Construtor João Alves interligando municípios; C: Ocupação de novos condomínios na Barra dos Coqueiros; D: Hotel situado na praia da Costa, sofrendo processo de erosão.

\subsection{Estatística de Ondas e Marés}

A partir dos dados gerados pelo SMC-Brasil (entre os anos de 1948 e 2008), para o ponto P1 (Ponto DOW - Downscaled Ocean Waves), com cota de 14,92m, é possível observar que as ondas provenientes de leste-sudeste (ESE) e as de Sudeste (SE), representam, respectivamente, aproximadamente 57\% e $42 \%$ das ondas incidentes neste ponto. A tabela 1 apresenta os parâmetros de altura de onda, período de pico e probabilidade de ocorrência para as direções de onda mais frequentes. Para casos relacionados às condições de tempestade (Hs12 e Tp12, valores em média superados somente 12 horas ao ano) e medianas (Hs50\% e Tp50\%) para cada uma das principais direções.

As ondas nesta região podem encontrar-se em condições normais (ondas sea), geradas pelo vento local, ou de tempestade (ondas swell), procedentes de tempestades em altas latitudes. Segundo Gagliardi (2013) em condições de tempestade, as ondas podem atuar como agentes erosivos nos sistemas costeiros por meio da elevação de altura, do período de trens de onda atuantes e do nível do. As ondas em condições normais, assim como as de tempestade, formam feições praiais a partir da troca de energia entre a 
XVII Simpósio Brasileiro

de Geografia Fisica Aplicada

I Congresso Nacional

de Geografia Física

\section{OS DESAFIOS DA GEOGRAFIA FÍSICA NA FRONTEIRA DO CONHECIMENTO \\ Instituto de Geociências - Unicamp \\ Campinas - SP \\ 28 de Junho à 02 de Julho de 2017}

atmosfera e oceano por meio do atrito entre e o vento e a superficie do mar, sendo este processo mais intenso com a ação de ondas do tipo swell de longos períodos.

$\mathrm{Na}$ avaliação das duas principais direções (ESE e SE), observa-se que a altura de onda em condições de tempestades anuais (Hs12) para as ondas de ESE foi de 2,57m e, para as de SE de 2,89m. Para as condições medianas, a altura de onda significativa (Hs50\%) foi de 1,38m para ondas provenientes de ESE e de $1,45 \mathrm{~m}$ para ondas provenientes de SE.

Os períodos de pico para as condições de tempestade (Tp12) foram de 14,84s para ondas de provenientes de ESE e de 16,26s para ondas de SE, ondas swell que chegam à praia com maior energia. Para as condições medianas, o período de pico (Tp50\%) foi de $8,28 \mathrm{~s}$ e de $8,34 \mathrm{~s}$, respectivamente, para ondas provenientes de ESE e SE.

Tabela 1 - Caracterização das estatísticas de ondas do ponto P1.

\begin{tabular}{|c|c|c|c|c|c|}
\hline Direção & Prob. direção & Hs 50\% & Tp 50\% & Hs 12 & Tp 12 \\
\hline E & 0.0017 & 1.1355 & 7.0947 & 1.8455 & 9.4068 \\
\hline ESE & 0.5708 & 1.3888 & 8.2840 & 2.5749 & 14.8424 \\
\hline SE & 0.4207 & 1.4547 & 8.3411 & 2.8980 & 16.2624 \\
\hline SSE & 0.0068 & 1.5413 & 8.5667 & 2.7888 & 15.6673 \\
\hline
\end{tabular}

Em relação ao regime de marés atuantes na região é do tipo mesomaré semi-diurna, apresentando duas marés altas e duas marés baixas a cada dia. Os resultados gerados pelo SMC - Brasil, mostram que o regime de oscilação do nível do mar é principalmente governado pela maré astronômica, com oscilações entre $\pm 1,3 \mathrm{~m}$, enquanto que as marés meteorológicas oscilam entre $\pm 0,2 \mathrm{~m}$ (figuras 3 e 4). A partir de alguns estudos (CAMARGO et.al. 2002), foi visto que a maré meteorológica pode ser definida como a diferença entre a maré observada e a maré astronômica. Segundo o autor, duas causas podem provocar a maré meteorológica: as variações de pressão atmosférica, que é responsável por menos de $10 \%$ do fenômeno, e a tensão de cisalhamento do vento sobre a superfície do oceano, que é o principal efeito atuante da maré meteorológica. Assim, a maré meteorológica é, portanto, responsável pelo aumento ou diminuição do nível do mar em relação as marés astronômicas observadas num dado local. Já os estudos em relação à maré astronômica, expoem que as variações de nível do mar relacionadas às marés de origem astronômica se diferenciam por apresentarem períodos muito mais amplos e tem sua origem por combinação de ciclos astronômicos, planetários e climáticos (NUNES, 2007), e é a principal atuante na área de estudo. 


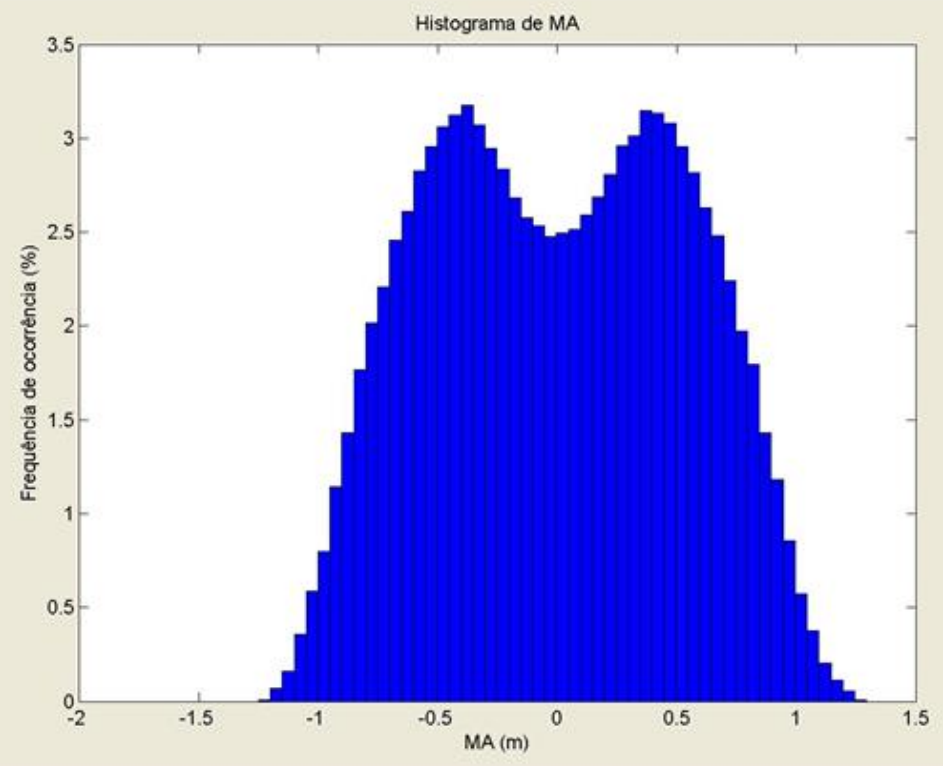

Figura 3: Histograma de frequência para Marés Astronômicas para a região marinha da Praia da Costa.

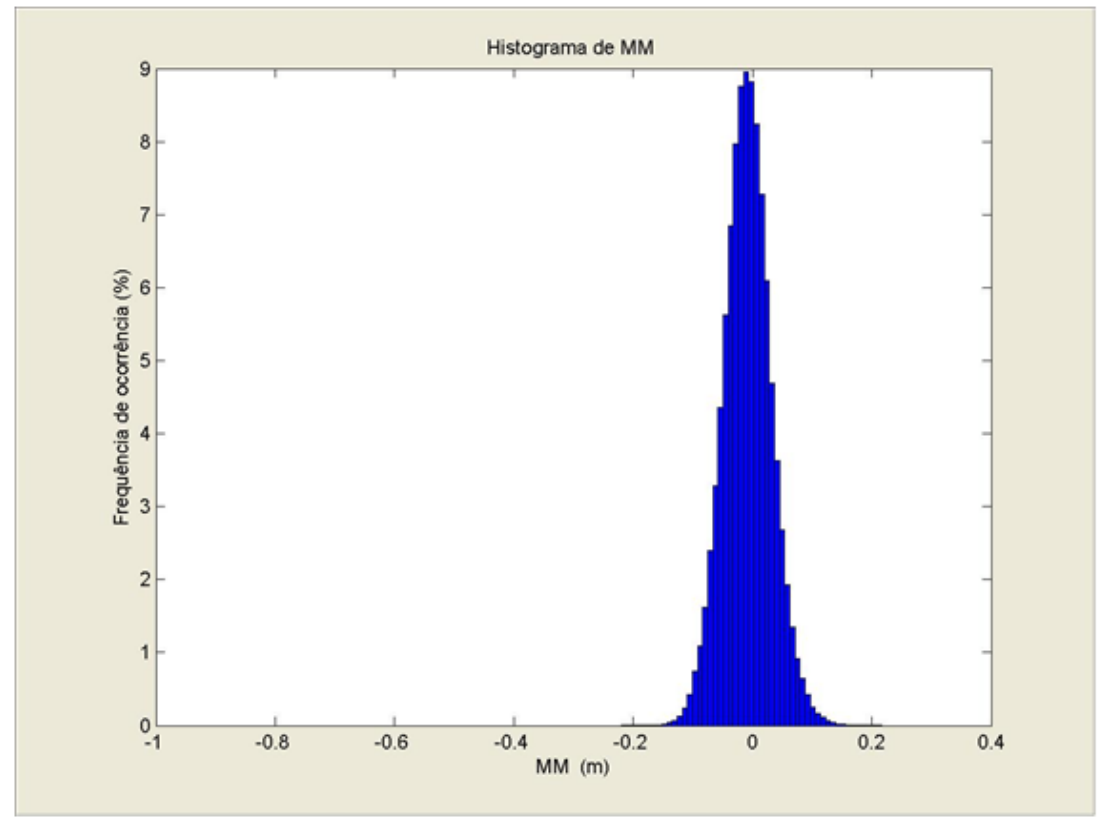

Figura 4: Histograma de frequência para Marés Meteorológicas para a região marinha da Praia da Costa.

\section{Conclusão}

O SMC representou-se como uma importante ferramenta de gestão, contribuindo para a caracterização e compreensão do clima de ondas local (altura de onda, período de onda, direção de onda, maré astronômica e maré meteorológica), que associado ao estudo realizado sobre a expansão urbana na região 
da praia da Costa, pode-se concluir que em virtude da expansão urbana em direção à linha de costa, já ocupando em alguns casos a zona de espraiamento, pode trazer mudanças na dinâmica costeira local. A ocupação dos terraços arenosos, dificultando os processos de infiltração, e as alterações da dinâmica hídrica natural, com os empreendimentos instalados nas zonas úmidas, torna esta região ainda mais vulnerável à inundação. Além disso, a retirada da vegetação e alteração na morfologia das dunas frontais diminui a proteção natural à sua retaguarda.

A combinação de eventos de tempestades com marés meteorológicas positiva, marés astronômicas de sizígia, pode resultar em situações de alto risco para ecossistemas e propriedades, com grandes impactos para este litoral. A partir desse conhecimento, pode-se melhor planejar a ocupação em áreas costeiras diminuindo os riscos de perdas socioeconômicas e minimizando os impactos decorrentes das mudanças ambientais. O município necessita de projetos e apoio da gestão costeira para haver um melhor controle e fiscalização de ocupação da área.

\section{REFERÊNCIAS}

ALMEIDA, L. R.; AMARO, V. E; MARCELINO, A. M. T; SCUDELARI, A. D. 2015. Avaliação do clima de ondas da praia de Ponta Negra (RN, Brasil) através do uso do SMC-Brasil e sua contribuição à gestão costeira. Revista de Gestão Costeira Integrada, vl. 15 n$^{\circ} 2$ pg. 135-151.

BRASIL. Constituição (1988). Emenda constitucional n. ${ }^{\circ}$ 9, de 9 de novembro de 1995. Lex: legislação federal e marginália, São Paulo, v. 59, p. 1966, out./dez. 1995.

CAMARGO, R.; HARARI, J.; BISCARO, T. S.; BIAZETO, B. 2002. Avaliação das previsões em maré meteorológica realizadas com o Princeton ocean model no laboratório MASTER/IAG/USP. XII Congresso Brasileiro de Meteorologia, Foz de Iguaçu, PR, Brasil.

CAMUS, P.; MENDEZ, F.J; MEDINA, R.; TOMAS, A.; IZAGUIRRE, C. 2013. High resolution downscaled ocean waves (DOW) reanalysis in coastal areas. CoastalEngineering, 72: 56-68.

COSTA, V. S. Território em mutação: a implantação de central geradora eólica em Sergipe. 2013. 131 f. Dissertação (Mestrado em Geografia) - Universidade Federal de Sergipe, São Cristóvão, SE.

ESTEVES, L. S.. Variabilidade espaço-temporal dos deslocamentos da linha de costa no Rio Grande do Sul. 2004. 139f. Tese de Doutorado, Programa de Pós-Graduação em Geociências, FURGS.

GAGLiARDI, M. H. 2013. Análise de Riscos Costeiros a Eventos Atmosféricos Extremos no Litoral Sul do Estado de São Paulo - Estudo de caso na região da Desembocadura de Cananéia,

MMA. Projeto orla: fundamentos para gestão integrada / Ministério do Meio Ambiente, Ministério do Planejamento, Orçamento e Gestão. - Brasília: MMA, 2006.

MARIA, L. Expansão urbana e qualidade ambiental no litoral de João Pessoa-PB. 2009.Dissertação de Mestrado (Programa de Pós-graduação em Geografia) - Centro de Ciências Exatas e da Natureza, Universidade Federal da Paraíba, João Pessoa.

NUNES, A. L. Determinação das marés meteorológicas na região da baía do espírito santo e sua influência na drenagem de águas continentais. 2007. 133f. Dissertação (mestrado) - Universidade Federal do Espírito Santo, Centro Tecnológico.

PEREIRA, P. S.; WELLINGTON, J. C. V.. Do território do vazio ao "paraíso urbano": o imobiliário-turístico na Barra dos Coqueiros (SE). VIII Congresso Norte Nordeste de Pesquisa e Inovação, Salvador, 2013. 
SMC-BRASIL. Documento síntese do seminário internacional Brasil - Espanha apoio à gestão da costa brasileira. 2013. 